\title{
ARTIFICIAL INTELLIGENCE (ONLINE RESOURCE): A PANACEA FOR SMES IN HEALTHCARE
}

\author{
Anuj Kumar*1, Asif Ali Syed², Anoop Pandey³ \\ 1. Aligarh Muslim University; \& Apeejay School of Management, Dwarka, India \\ 2. Department of Business Administration, Aligarh Muslim University, India \\ 3. Hemvati Nandan Bahuguna Garhwal University, Uttarakhand, India
}

Correspondence: anujsmooth@gmail.com

\begin{abstract}
This paper presents a review of the most recent and popular research papers on the use of artificial intelligence in the healthcare sector. SMEs consist of $60-65 \%$ of Indian medical device market. Many doctors are operating through private hospitals which come under the category of SMEs segment. Technology is proving to be a boon for all the sectors, artificial intelligence an emerging technology has the potential to change the fortune of SMEs in health care sector. In this paper there will be discussion on how artificial intelligence can help the healthcare sector in different ways. SMEs working in healthcare can take a learning from this paper and can utilize it for betterment.
\end{abstract}

\section{KEYWORDS}

Artificial Intelligence, Healthcare, Technology, SMEs, Management

This paper was presented at the AICTE International Conference on Circular Economy, Management and Industry, Bharati Vidyapeeth's Institute of Management Studies and Research, Navi Mumbai and Apeejay School of Management, Dwarka, Delhi, India. October 2021

\section{INTRODUCTION}

Recently healthcare industry is facing a lot of trauma and panic around the world. COVID-19 has shocked the healthcare industry. Healthcare professionals have encountered different types of attacks consist of physical assault by patients and relatives, service denial by medical staff, obstructions, cyber-attacks, and psychological threats to the doctors. COVID-19 is getting adverse as more than six lakhs of death reported in the USA, 4.2 lakhs death in India, 5.5 lakhs death in Brazil, 1.2 lakhs death in the UK, and nearly 1.2 lakh people lost lives in Italy. [1] The healthcare industry is in a fragile state, and doctors are looking for practical solutions that can help them speed up the work. In this challenging situation [2], the adoption of technology can be a boon for the healthcare industry. [3, 4] Various departments in the healthcare industry facing different types of problems in dealing with patients. [5] There are already discussions about video consultations and other usages of technology to improve the procedures during COVID-19. [6, 7]

SMEs' role cannot be denied either in developed or developing nations. Many emerging nations, such as India, China, Malaysia, and Indonesia, want to upgrade themselves as developed nations. For categorization as developed nations, the emerging nations need to move 
towards sustainable growth. The emerging nations need to improve the income gap between people, per capita income, employment, security, health conditions, and overall living conditions of the people. In short, a nation needs overall growth and economic development. The role of SMEs is much more important for developing and emerging nations in reducing poverty, improving the income gap, generating employment, and increasing the overall GDP of the nation. SMEs can be a game-changer if the government understands its responsibility to develop them. In the medical sector there are many SMEs looking for possible solution for their problem. Artificial intelligence can solve their problem and take them towards continuous growth.

In many developing nations, SMEs are in bad shape because they have not updated themselves. SMEs are facing financial burdens and competition with top firms. They need to contribute to the nation's growth and achieve economies of scale. The SMEs are expected to grow with limited sources and support. Further, their contribution is prolific to the nation. Online resources in the form of electronic commerce, social media, technology 4.0, ICT tools, etc., can help SMEs in achieving desired growth. Thereafter, SMEs can help a nation towards sustainable growth and upgrading to the category of developed nations. Currently, the adoption of e-resources is in the nascent stage in India and many other developing nations.

This paper reviews the recent literature on " $\mathrm{Al}$ and the healthcare sector" and presents the findings. This study holds salient implications for practitioners and researchers as it elucidates the potentials of $\mathrm{Al}$ applications in the healthcare sector which become essentially significant as the tremors of the COVID-19 epidemic have ushered in a new era of healthcare issues around the world. The findings of this research can be helpful for the SMEs in the healthcare segment to improve their overall processing.

\section{LITERATURE REVIEW}

In this paper, fifteen different articles (top-cited) have been reviewed, which are based on the usage of $\mathrm{Al}$ in the healthcare industry. Many small and medium enterprises have already adopted technology 2.0 social media tools to improve their marketing and sustainability responses. [8, 9]

\section{TABLE 1 - SUMMARY OF LITERATURE REVIEW- (AUTHORS' OWN COMPILATIONS)}

\begin{tabular}{|c|c|c|}
\hline & Authors & Al and healthcare \\
\hline 1 & [10] & $\begin{array}{l}\text { The authors argued that } \mathrm{Al} \text { could solve the human resource crisis in the } \\
\text { healthcare industry because it can help in fast diagnosis, quick decision } \\
\text { making, and data analytics. }\end{array}$ \\
\hline 2 & [11] & $\begin{array}{l}\text { The authors have argued that } \mathrm{Al} \text { cannot replace human resources } \\
\text { altogether, but it can help majorly in four areas- patient administration, } \\
\text { decision making, monitoring, and interventions. }\end{array}$ \\
\hline 3 & [12] & $\begin{array}{l}\text { The authors argued that healthcare professionals need something to help } \\
\text { them in early detection and cure against the COVID-19 pandemic. Al-based } \\
\text { technology can be used for early detection, analysis, screening, and tracking } \\
\text { the COVID-19 patients. }\end{array}$ \\
\hline 4 & [13] & $\begin{array}{l}\text { Both Al and big data can help in three ways to counter the COVID-19 } \\
\text { pandemic. In the shorter term, Al and big data can help identify and } \\
\text { diagnose COVID-19 cases. In the medium term, these technologies can help } \\
\text { identify therapeutic options, and in a long time, technologies can help share } \\
\text { data and information with proper protocols. }\end{array}$ \\
\hline 5 & [14] & $\begin{array}{l}\text { The authors have argued that Al-based systems can help the healthcare } \\
\text { industry in risk assessment at the individual level, hospital level, and national } \\
\text { level. Al models can be applied to evaluate health risks on email, phone calls, } \\
\text { and messages at the personal level. }\end{array}$ \\
\hline 6 & {$[15]$} & $\begin{array}{l}\text { There is a need to reduce human intervention in the treatment and } \\
\text { medication of COVID-19 patients. Al and Machine learning can improve }\end{array}$ \\
\hline
\end{tabular}




\begin{tabular}{|c|c|c|}
\hline & & $\begin{array}{l}\text { diagnosis, treatment, and cure. Better forecasting is possible with the } \\
\text { practical usage of Al. }\end{array}$ \\
\hline 7 & {$[16]$} & $\begin{array}{l}\text { Al can help in multiple ways to deal with the COVID-19 pandemic. It is useful } \\
\text { for tracking, knowledge sharing, prediction, social distancing, and medical } \\
\text { chatbots. Al is also focusing on prevention strategies on COVID-19. }\end{array}$ \\
\hline 8 & {$[17]$} & $\begin{array}{l}\text { Al and other digital technologies can help prevent, diagnose, and treat } \\
\text { COVID-19 disease. It can also help in surveillance. }\end{array}$ \\
\hline 9 & {$[18]$} & $\begin{array}{l}\text { Al-based algorithms helped the companies such as BlueDot and Metabiota } \\
\text { in the early detection of the virus, and it also helps in the prevention of the } \\
\text { same. With the usage of technology, detection and prevention of viruses are } \\
\text { possible within a specified time. }\end{array}$ \\
\hline 10 & [19] & $\begin{array}{l}\text { Al can help the healthcare segment in predicting the spread of infectious } \\
\text { diseases like COVID-19. It can help the healthcare segment is much more } \\
\text { focused and disease-specific analysis and interventions. Al can control the } \\
\text { risk of infectious disease }\end{array}$ \\
\hline 11 & [20] & $\begin{array}{l}\text { With Al usage, the healthcare industry is moving in a fast-forward direction as } \\
\text { it is very much helpful in fast detection, diagnosis, and treatment. It helps in } \\
\text { making effective and efficient decisions. }\end{array}$ \\
\hline 12 & [21] & $\begin{array}{l}\text { Al-based applications can help streamline the dental healthcare workforce; } \\
\text { they can reduce healthcare expenses and eventually helps in predictive, } \\
\text { preventive, and participation-based dentistry. }\end{array}$ \\
\hline 13 & [22] & $\begin{array}{l}\text { Al helps improve clinical care, therapies, efficiencies, and testing in the } \\
\text { healthcare segment. It is also useful in building trust and engagement among } \\
\text { the healthcare segment by practical usage of technology. }\end{array}$ \\
\hline 14 & [23] & $\begin{array}{l}\text { It helps minimize human cognitive functions by adding a prospect of } \\
\text { automation in the healthcare industry. Al is useful in preventing all major } \\
\text { diseases like cancer, neurology, and cardiology. Practitioners are using Al in } \\
\text { NLP. }\end{array}$ \\
\hline 15 & [24] & $\begin{array}{l}\text { Al can help in early warnings, tracking, detection, diagnosis, prognosis, and } \\
\text { social control, but there are certain deadlocks like lack of data or too much } \\
\text { data. The practical usage of Al is still a problem. }\end{array}$ \\
\hline
\end{tabular}

Based on the above literature, it can be concluded that $\mathrm{Al}$ can be helpful for the effective working of the healthcare industry in one or more ways. Figure 1 presents the summarized crux of the above cited fifteen papers through a word cloud.

FIGURE I. WORD CLOUD USING THE TEXT OF FIFTEEN RESEARCH PAPERS USED IN THE STUDY

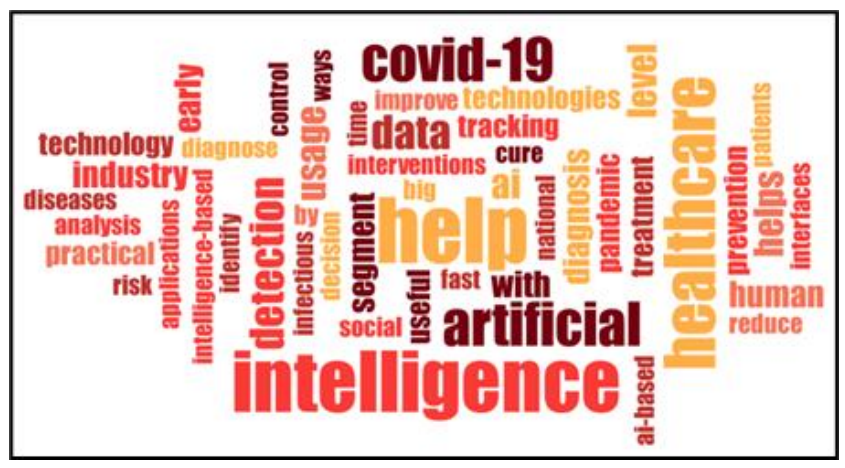

Source: Author's own compilation using wordsift.org 
Based on the analysis of the top-cited research papers related to the theme of the study, the two themes created are the "positive implications of using $\mathrm{Al}$ in the health care sector" and the "limitations of Al in the healthcare sector". The subthemes under the first theme of "positive implications of using Al in the health care sector" are "fasttracking, diagnosis, and treatment", "empower healthcare sector", "reduction in costs", "streamlining of work", and "fast information sharing and decision making". The subthemes under the second theme, "limitations of $\mathrm{Al}$ in the healthcare sector", are "lack of emotions", "fear of unemployment in medical staff/workers", and "training and the right platform".

\section{A. POSITIVE IMPLICATIONS OF USING AI IN THE HEALTH CARE SECTOR: SMES CAN LEARN}

1) Fast-tracking, diagnosis, and treatment: During COVID19, the whole medical industry faced the need for fasttracking of disease, diagnosis, and treatment. Fast diagnosis and treatment are not only limited to COVID19 disease elsewhere. Also, healthcare professionals need to detect different types of viruses spreading at a rapid pace. Al-based algorithms and techniques help in the fast detection of disease. [25] Al-based algorithms can collect information from a large amount of data and provide correct output. Like all other industries, the healthcare industry is also in the dearth of human resources. Al can overcome the shortage of human resources, but it cannot replace them. Al helps in effective initial screening, diagnosis and ultimately, the algorithms helped find a relationship between treatment technique and patient outcomes.

2) Empower the healthcare sector: Al can empower the healthcare industry because it will help in the reduction of human interaction. The human workforce is limited, especially in developing countries. The pandemics like COVID-19 have highlighted the shortage of medical professionals all around the world. Al can empower the healthcare industry by providing necessary skills in terms of technology in the present and future. The minimum doctor to the patient ratio recommended by World Health Organization is 1: 1000, but this ratio is not achieved in many countries. The shortage of doctors is observed. Countries like China and India are growing rapidly while infrastructure and healthcare facilities are very limited. Al is needed to empower healthcare from the base. Technology can help all the patients in accessing the medicine in the form of telemedicine. Using machine learning and statistical techniques, it is possible to analyze large data sets and notice the trends.

3) Reduction in costs: All industries and sectors want to achieve economies of scale. The healthcare industry is also on the same lines. Healthcare professionals and doctors are looking for new ways to reduce costs and increasing the speed of work. Al can help develop technology at a much lower price because efficiency increases, and diagnosis will be much more focused. Al-based health care allows doctors to judge out medical professionals about a meaningful pattern of data collection, and it reduces time, cost, and overall energy. Adopting $\mathrm{Al}$ is no more a choice; it is a must for the coming generations.

4) $\mathrm{Al}$ can streamline the work: The human resource shortage is visible in the healthcare industry. In such time, $\mathrm{Al}$ is useful in creating virtual nurses and medical assistants. Those nurses and medical assistants can monitor the activities and medication timetables. That fake intelligence-led medical nurses and assistants can help in solidifying the interconnection between patients and doctors. The necessary information can be provided to the doctors. Al modelling can be used to understand text and images. In daily life, medical professionals consume a lot of time in the documentation process, data entry, and sorting.

5) Fast information sharing and decision making: While the whole world is facing the COVID-19 problem, information sharing is quite relevant nowadays, at least in the medical domain. Doctors around the world are working to find a vaccine for the COVID-19 disease. The whole world is facing this pandemic, so information sharing is a must between doctors and medical practitioners. The Al-based platform can help in information sharing based on specific patient data. Al can also be used to track the patterns identified in a patient to determine the probability of success or failure of a specific medicine on the patient's body. The medical practitioners want to know the root causes of the problem and their solution to reduce potential medical risks. The decision-making is too fast by utilizing the Al-based process. 


\section{B. LIMITATIONS OF AI IN HEALTHCARE}

1) Lack of emotions: Machines, programs, and algorithms do not work on emotions. Whether it is surgical robots or algorithms, they all work as per a specific program set. The systems are not logical in nature. They do not carry any emotions or sympathy towards patients. The human interaction always involves an emotional touch between the patient and medical staff, but that touch is missing in the machine. Medical staff is also flexible in their approach because there is trust-building between medical patients and staff members. Devices are not dependent on trust and relationship building. The most significant setback is that medical practitioners can change their approach when operations do not go as per plan. Occasionally, medical staff go beyond the rules to save a patient's life because of emotional connection. Machines can not violate the regulations, and they work as per set standard planning. Social and emotional intelligence is also necessary for effective working [26]. Al-based instruments can work with minor errors, but they can create problems for both patients and medical staff when there is a significant diversion.

2) Fear of unemployment in medical staff/workers: Albased systems can create a fear of unemployment and job insecurity in the minds of those medical professionals who are aligned in analyses, diagnosis, etc. However, whether technology is an overall replacement of the human in the medical profession or will act as a value-added tool. There are chances that the machine can stick, or the algorithm may fail; in that situation, defective diagnosis may occur. Al-run system is based on information collected through various datasets. Suppose there is an error in uploading the data, then it can create problems in the overall structure and effective functioning. The lack of information leads to inaccurate diagnosis and decision-making in the system.

3) Training and the right platform: It are not easy to work on an Al-based platform without adequate training. The technology adoption is still in the initial phase, and it is needed to be refined. Medical practitioners need to find the right partners and invest carefully in implementing the right platforms to adopt $\mathrm{Al}$. $\mathrm{Al}$ cannot be implemented in each type of venue. Good precision and planning are required before implementing such a solution, and the training of staff members is a must.

\section{CONCLUSION}

Al is an emerging and promising technology for detecting early coronavirus infections and monitoring the state of affected individuals. By building helpful algorithms, it can considerably improve treatment uniformity and decisionmaking. $\mathrm{Al}$ is beneficial in the treatment of COVID-19 afflicted patients and properly cost-effectively monitoring their health. SMEs in healthcare sector have limited finance, Al based algorithm are cost-effective in nature. It is also beneficial to facilitate viral research by analyzing the existing data. Al can aid in creating effective treatment regimens, preventative initiatives, and drug and vaccine development and thus empower the health care sector.

\section{References}

1. Worldometer, "COVID-19 CORONAVIRUS PANDEMIC," 2021. [Online]. Available:

https://www.worldometers.info/coronavirus/. [Accessed 23 February 2021]

2. A. Kumar and D. N. Ayedee, "An Interconnection between COVID-19 and Climate Change Problem,"Journal of Statistics and Management Systems, vol. 25, pp. 1-21, 2021.

3. A. Kumar and N. Ayedee, "Technology Adoption: A Solution for SMEs to overcome problems during COVID-19,"Academy of Marketing Studies Journal, vol. 25 , no. 1, pp. 1-16, 2021.

4. A. Kumar, D. A. A. Syed and D. A. Pandey, "How Adoption of Online Resources Can Help Indian SMEs in Improving Performance during COVID-19 Pandemic,"Test Engineering and Management, vol. 83, no. 83, pp. 3394-3400, 2020.

5. D. A. Sudrajat, T. O. Indrianti, E. Supriatin, S. N. Hayati and L. Lindayani, "Nurse burnout: comparing public and private hospitals in Indonesia,"British Journal of Healthcare Management, vol. 27, no. 2, 2021.

6. L. Holdsworth, D. Provan, G. Nash, M. Beswick, C. Curran, I. Colhart and A. Hunter, "Can webinars support the implementation of video consultations at pace and scale within the allied health professions?,"British Journal of Healthcare Management, vol. 27, no. 2, pp. 1-9, 2021.

7. M. W. Baqai, U. Hani, N. Shahzad and R. Alvi, "Beep or alert: evaluating WhatsApp vs pagers for 
communication between hospital staff,"British Journal of Healthcare Management, vol. 27, no. 1, 2021.

8. A. Kumar and A. Pandey, "Usage of social media as an integrated marketing tool in business," Journal of Management, vol. 5, no. 3, pp. 123-128, 2018.

9. A. Kumar and R. Aggarwal, "Sustainable development through social media tools," Journal of Management, vol. 5, no. 5, pp. 47-51, 2018.

10. B. Mesko, G. Hetényi and Z. Győrffy, "Will artificial intelligence solve the human resource crisis in healthcare?,"BMC Health Services Research, p. 18, 2018.

11. S. Reddy, J. Fox and M. P. Purohit, "Artificial intelligence-enabled healthcare delivery,"Journal of the Royal Society of Medicine, vol. 112, no. 1, pp. 2228, 2019.

12. R. Vaishya, M. Javaid, I. H. Khan and A. Haleem, "Artificial Intelligence (AI) applications for COVID-19 pandemic,"Diabetes Metabolic Syndrome, vol. 14, no. 4, 2020.

13. N. L. Bragazzi, H. Dai, G. Damiani, M. Behzadifar, M. Martini and J. Wu, "How Big Data and Artificial Intelligence Can help Better Manage the COVID-19 Pandemic,"International Journal of Environmental Research and Public Health, vol. 17, pp. 1-8, 2020.

14. M. V. D. Schaar, A. M. Alaa, A. Gimson, A. Ercole, P. Lio, Jarrett and Daniel, "How artificial intelligence and machine learning can help healthcare systems respond to COVID-19,"Machine Learning, vol. 110, pp. 1-14, 2020.

15. S. Lalmuanawma, J. Hussain and L. Chhakchhuak, "Applications of machine learning and artificial intelligence for Covid-19 (SARS-CoV-2) pandemic: A review,"Chaos Solitons Fractals, vol. 139, 2020.

16. D. Calandra and M. Favareto, "Artificial Intelligence to fight COVID-19 outbreak impact: an overview,"European Journal of Social Impact and Circular Economy, pp. 84-104, 2020.

17. D. Golinelli, E. Boetto, G. Carullo, M. P. Landini and M. P. Fantini, "How the COVID-19 pandemic is favoring the adoption of digital technologies," 2020. [Online]. Available:

https://www.medrxiv.org/content/medrxiv/early/2020/ 05/01/2020.04.26.20080341.full.pdf. [Accessed 18 February 2021].

18. Z. Allam, G. Dey and D. S. Jones, "Artificial Intelligence (AI) Provided Early Detection of the Coronavirus
(COVID-19) in China and Will Influence Future Urban Health Policy Internationally,"MDPI, vol. 1, pp. 156-165, 2020.

19. K. Jain, "Artificial Intelligence Applications in handling the Infectious Diseases,"Primary Health Care, vol. 10, no. 5, pp. 351-354, 2020.

20. D. Khanna, "Use of artificial intelligence in healthcare and medicine,"International Journal of innovations in Engineering Research and technology, vol. 5, no. 12, pp. 21-24, 2018.

21. F. Schwendicke, W. Samek and J. Krois, "Artificial Intelligence in Dentistry: Chances and Challenges,"Journal of dental research, vol. 99, no. 7, pp. 769-774, 2020.

22. D. Horgan, M. Romao, S. A. Morre and D. Kalra, "Artificial Intelligence: Power for Civilisation - and for Better Healthcare,"Public health genomics, vol. 22, pp. 145-161, 2019.

23. F. Jiang, Y. Jiang, H. Zhi, Y. Dong and H. Li, "Artificial intelligence in healthcare: past, present and future,"Stroke and Vascular Neurology, vol. 2, pp. 230243, 2017.

24. W. Naudé, "Artificial Intelligence against COVID-19: An Early Review," Bonn, 2020.

25. A. L. Fogel and J. C. Kvedar, "Artificial intelligence powers digital medicine,"NPJ digital medicine, vol. 1, no. 1, pp. 1-4, 2018.

26. M. FRANKOVSKÝ, Z. BIRKNEROVÁ, L. ZBIHLEJOVÁ, A. KUMAR and N. MARWAH, "Social intelligence in the Cultural Context: Comparison of Indian and Slovak Managers,"Organizational Psychology, vol. 9, no. 3, pp. 8-19, 2019. 